\title{
Variation of nitrate and bacterial diversity along soil profiles in manure-disposal maize field and adjacent woodland
}

\author{
Yujia Cai ${ }^{1}$, Ju-Pei Shen ${ }^{1}$, Hong J. Di², Li-Mei Zhang ${ }^{1}$, Chengjun Zhang ${ }^{3}$, and Ji-Zheng $\mathrm{He}^{4}$ \\ ${ }^{1}$ Research Centre for Eco-Environmental Sciences Chinese Academy of Sciences \\ ${ }^{2}$ Lincoln University \\ ${ }^{3}$ Beijing Academy of Agriculture and Forestry Sciences \\ ${ }^{4}$ Fujian Normal University
}

May 5, 2020

\begin{abstract}
Intensified livestock system produced large amount of bio-waste, and improper disposal of livestock manure has led to severe environmental consequences. However, knowledge about the time-dependent changes of manure-derived nitrate and soil bacterial diversity along the soil profiles is limited. In this study, vertical variation of soil bacterial diversity and composition in a manureamended maize field and adjacent non-manured woodland was investigated using high-throughput sequencing technique in spring and autumn along a 1-meter profile depth. The results showed that higher amount of nitrate was detected along the soil profile loaded with cattle manure compared with the adjacent non-manured woodland, and soil $\delta 15 \mathrm{~N}-\mathrm{NO} 3-$ composition further corroborated the manure-derived nitrate in the maize field. No significant difference in bacterial richness between the two land uses was found, while clear separation of bacterial structure was detected even to the deep soil layers. Canonical correspondence analysis showed that soil properties were the major factors influencing the variance of bacterial community composition. Bacterial network is more complex in the maize field than in the adjacent woodland. Soil bacterial communities among the depth profiles in the two land uses tended to be more phylogenetically clustered than expected by chance, and were more likely to be clustered along the depth. These findings suggested that bacterial $\beta$ diversity was strongly related to multinutrient properties with high livestock manure load, and had important implications for assessing the environmental impacts on below-ground biodiversity in sandy loam soils.
\end{abstract}

\section{KEYWORDS}

Manure disposal, Nitrate isotope, Bacterial community assembly, Spatio-temporal variation, Land use

\section{INTRODUCTION}

China's livestock industry has undergone a vast transition during the last four decades, providing the majority of meat and other dairy products supporting the rapidly growing human population. However, increasing demand for livestock generated large amount of bio-waste. It has been documented that over 3.8 billion tons of livestock waste was produced per year in China and the nitrogen $(\mathrm{N})$ in the waste accounted for $38 \%$ of the agricultural $\mathrm{N}$ released into the environment (data from China Rural statistical Yearbook, 2014). Additionally, the increased availability of synthetic N (mostly chemical fertilizers) contributed to the abandonment of livestock waste instead of re-using in agricultural system (Bai et al., 2018). As a consequence, large areas of lands are necessary for those redundant livestock manure disposal (Jia et al., 2018), with severe environmental issues for terrestrial and aquatic ecosystems.

Livestock waste confers benefits to soils if managed and used properly as it contains abundant carbon (C), N, phosphorus (P) and other trace elements, improving soil fertility and quality. However, livestock production, 
consuming $1 / 3$ of global agricultural land and $32 \%$ of world's freshwater, is a primary source of greenhouse gases such as nitrous oxide $\left(\mathrm{N}_{2} \mathrm{O}\right)$ and methane $\left(\mathrm{CH}_{4}\right)$, and of $\mathrm{N}$ and $\mathrm{P}$ in water leading to eutrophication (Yu et al., 2019). A large amount of $\mathrm{N}$ in livestock manure is finally converted into nitrate $\left(\mathrm{NO}_{3}{ }^{-}\right)$by microorganisms and accumulates in the soil profile (Ju et al., 2007; Yang et al., 2006; Zhou et al., 2016). Concerning the severe impact of nitrate on aquatic and terrestrial ecosystems, it is of particular importance to distinguish various nitrate sources, e.g. from sewage or manure. Dual isotope approach using nitrogen and oxygen isotopic composition has been successfully applied in differentiating the numerous nitrate sources and identifying the $\mathrm{N}$ role in various processes (Krapac et al., 2002; Liu et al., 2013; Wang et al., 2017). However, knowledge about the time-dependent changes of manure-derived ${ }^{15} \mathrm{~N}$ and ${ }^{18} \mathrm{O}$ in the soil profile is limited.

Soil harbor enormously diverse microorganisms driving a wide range of ecosystem processes including soil nutrients cycling, organic matter decomposition and detoxification of contaminants (Bardgett \& van der Putten, 2014). Hence insights into the role of microbial community can also explain how livestock manure influences ecosystem processes and function, as well as provide a more effective strategy to recycle and utilize the nutrients (Feng et al., 2015). Numerous studies have reported that organic fertilization like animal manure can improve soil fertility, impact microbial diversity and alter community structure and composition compared with chemical fertilization (Ashworth et al., 2017; Hartmann et al., 2015; Lin et al., 2019; Sun et al., 2015; Tian et al., 2015; Yang et al., 2017). However, few studies have explicitly addressed the succession feature of bacterial community along the soil profile seasonally, especially from the start of manure application. Previous research suggested that environmental filtering is more important than stochastic process in agricultural system due to the manure disturbance (Yu et al., 2019), and vice versa for a less disturbed environment, like forest (Mayfield \& Levine, 2010). It has been widely accepted that microbial community assembly is driven by deterministic or stochastic processes (Jiao et al., 2018; Stegen et al., 2012), while more and more studies suggested that the assembly process generally performed together but not independently (Powell et al., 2015; Zheng et al., 2013). Therefore, understanding the factors influencing the microbial community assembly process along the soil profile with the addition of manure is critical to assessing the environmental consequences of livestock waste disposal. Livestock manure is a considerably labile and C-rich source of resource and energy, which would likely activate r-strategy microbial taxa (Hartmann et al., 2015; Ho et al., 2017). In our previous study, we found shifts of soil bacterial community structure in organic manure treated soil using finger-printing methods (Shen et al., 2010). Feng et al (2015) further suggested that species Bacillus asahii responded most distinctly to manure addition, which become dominant in organic manure fertilized soils. However, which species would disappear along the application of manure is still unknown. Here we investigated the spatio-temporal variation of bacterial community in a long-term cattle manure loaded site near a dairy farm. We also collected the adjacent forest soil for comparison. We hypothesized that along the soil profile, nutrient availability might drive variation of bacterial community composition with r-strategy taxa responding most strongly with time. The aim for this study was to investigate (1) nitrate accumulation and leaching potential along the soil profile; (2) the most distinctly bacterial group in response to long-term manure loading; (3) the seasonal and vertical assembly of soil bacterial community and their factors in a sandy loam soil. Our study provides important information for understanding how the complex of soil bacterial community responds to anthropogenic disturbance, especially the abandonment of livestock waste and land use transformation.

\section{MATERIALS AND METHODS}

\subsection{Site description and sample collection}

The sampling site is located in Yanqing District $\left(40^{\circ} 29^{\prime} \mathrm{N}, 115^{\circ} 56^{\prime} \mathrm{E}\right)$, Beijing, China, with a temperate continental monsoon climate. The annual temperature and precipitation was $8^{\circ} \mathrm{C}$ and $400-500 \mathrm{~mm}$, respectively. Most of the rainfall occurs between July and September. The soil is classified as aquic inceptisol with a bulk density of $1.31 \mathrm{~g} \mathrm{~cm}^{-3}$, and a sandy loam texture. There is a local dairy farm sitting within this area with a total of over two hundred cattle, producing around $4,000 \mathrm{t} \mathrm{a}^{-1}$ livestock waste loading into the maize fields near the daily farm (Figure 1). Therefore, three maize fields each with over $100 \times 100 \mathrm{~m}$ size 
were selected as three experiment plots, and each received cattle manure with $4 \times 10^{4} \mathrm{~kg} \mathrm{ha}^{-1}$ without any other fertilizers every spring for ten years. Soil samples were also collected from three adjacent woodlands with secondary forest developed from abandoned cropland for over ten years receiving no dairy manure or chemical fertilizers.

Sampling along a 0-100 cm profile including 0-20, 20-40, 40-60, 60-80 and 80-100 cm depth took place in May and October in 2018 just after maize seeds were sown and maize harvested, respectively. For each plot, 5 soil cores from each plot were collected with a hand auger and homogenized into a soil sample for each depth. Therefore, a total of 60 soil samples were obtained from two land uses for two seasons. After removing large pieces of rocks and plant material, soils collected from fields were transported to the laboratory immediately, and passed through a $2.0-\mathrm{mm}$ sieve. Samples were preserved at $4{ }^{\circ} \mathrm{C}$ and $-20{ }^{\circ} \mathrm{C}$ for further soil properties and molecular analysis, respectively.

\subsection{Soil physicochemical properties determination}

Measurement of soil properties were carried out following the methods of the soil agrichemical analysis (Lu, 2000). Soil pH was measured with a METLER TOLEDO FE20 at a soil/water ratio $(\mathrm{m} / \mathrm{m})$ of 1:1. Soil moisture content was determined after drying at $105^{\circ} \mathrm{C}$ for $12 \mathrm{~h}$. Soil organic matter was calculated with organic carbon determined with potassium dichromate and sulfuric acid. Total carbon (TC) and total nitrogen (TN) were measured by the elemental analyzer (Vario EL III, Elementar). Dissolved organic carbon (DOC) and dissolved organic nitrogen (DON) were measured by TOC/TN analyzer (Multi N/C Model 3100, Analytic Jena, Germany). Ammonium-N $\left(\mathrm{NH}_{4}{ }^{+}-\mathrm{N}\right)$ and nitrate- $\mathrm{N}\left(\mathrm{NO}_{3}{ }^{-} \mathrm{N}\right)$ were extracted from $6.0 \mathrm{~g}$ fresh soil with $1.0 \mathrm{~mol} \mathrm{~L}^{-1} \mathrm{KCl}$ solution (soil/extract ratio of 1:5) and shaken for $1 \mathrm{~h}$ at $180 \mathrm{rpm}$. The soil extract was analyzed by continuous flow analyzer (AA3, SEAL, Germany).

\section{$2.3 \Sigma o \iota \lambda \delta^{15} \mathrm{~N} \alpha \nu \delta \delta^{18} \mathrm{O}-\mathrm{NO}_{3}{ }^{-} \sigma \tau \alpha \beta \lambda \varepsilon \iota \sigma o \tau o \pi \varepsilon \alpha \nu \alpha \lambda \psi \sigma \iota \varsigma$}

The concentration of $\delta^{15} \mathrm{~N}$ and $\delta^{18} \mathrm{O}$ of natural nitrate $\mathrm{NO}_{3}{ }^{-}$was measured using denitrifier method (Sigman et al., 2001). Briefly, soil $\mathrm{NO}_{3}{ }^{-}$was extracted from $10.0 \mathrm{~g}$ fresh soil sample by ultrapure water at a soil/water ratio of 1:5 with shaking $(180 \mathrm{rpm})$ for $1 \mathrm{~h}$. Then $\delta^{15} \mathrm{~N}$ and $\delta^{18} \mathrm{O}$ isotope ratios of the extracted $\mathrm{NO}_{3}{ }^{-}$was determined based on $\mathrm{N}_{2} \mathrm{O}$ produced by cultured denitrifying Pseudomonas aureofaciens that converts $\mathrm{NO}_{3}{ }^{-}$ to $\mathrm{N}_{2} \mathrm{O}$ and analyzed on a Trace-Gas/Isotope Ratio Mass Spectrometry (IRMS, Isoprime100, UK) calibrated with ultra-high purity $\mathrm{N}_{2}$ gas against air $\mathrm{N}$ in Chinese Academy of Agricultural Sciences. The stable isotope ratios are expressed in delta $(\delta)$ units and a per mil (

\subsection{DNA extraction and Illumina MiSeq sequencing}

Soil DNA was extracted from $0.5 \mathrm{~g}$ frozen soil using the FastDNA spin kit (DNeasyß Power Soil@ Kit (100), QIAGEN, Germany) according to the manufacturer manual. DNA quality was assessed by a NanoDrop ND1000 Spectrometer (NanoDrop, Thermo Scientific, USA) at the wavelength of 260/280 $\mathrm{nm}$. DNA samples were stored at $-40 \operatorname{deg} \mathrm{C}$ for further analysis.

The V4-V5 region of the bacterial 16S rRNA gene were amplified by PCR using primers 338F (ACTCCTACGGGAGGCAGCA) and 806R (GGACTACHVGGGTWTCTAAT) (Lee et al., 2012). Triplicate PCR reactions for each sample was executed in $20 \mu \mathrm{L}$ mixture containing $4 \mu \mathrm{L}$ of $5 \times$ FastPfu Buffer, $2 \mu \mathrm{L}$ of $2.5 \mathrm{mM}$ dNTPs, $0.8 \mu \mathrm{L}$ of forward and reverse primer $(5 \mu \mathrm{M}), 0.4 \mu \mathrm{L}$ of FastPfu Polymerase, and $10 \mathrm{ng}$ of template DNA in ABI GeneAmpß 9700. Purified PCR products were pooled in equimolar and paired-end sequenced $(2 \times 250)$ on an Illumina MiSeq platform (Majorbio Bio-Pharm Technology Co. Ltd., Shanghai, China) following the standard protocols. The Quantitative Insight into Microbial Ecology (QIIME V1.9.1) pipeline (Caporaso et al., 2010) was used to process the raw sequences. A chimera filtering approach UPARSE was applied to bin the sequences into operational taxonomic units (OTUs) at the $97 \%$ sequence identity level (Edgar, 2013). As an even depth of sampling is required for diversity comparison, samples were randomly rarefied according to the lowest number (i.e. 17,113 sequences) among all the samples for downstream analysis. The rarefied OTU was used to calculate alpha diversity (OTU richness: observed number of OTUs, Shannon index) and community dissimilarity (Bray-Curtis dissimilarity distance). The raw reads were deposited into 
the NCBI Sequence Read Archive (SRA) database with the project accession number PRJNA603198.

\subsection{Co-occurrence network analysis}

Network analysis was performed on the rarefied OTU table and only OTUs with relative abundances over $0.1 \%$ and presented in at least 3 samples were included. The co-occurrence network analysis was executed in the CoNet 3 plugin for Cytoscape 3.7.1. For each network, node attributes were computed by bootstrapping approach with 1,000 iterations. Cluster Viz, a plugin in Cytoscape was used to find clusters in a network. Network topological parameters were calculated by the NetworkerAnalyzertool in Cytoscape 3.7.1. Networks were constructed based on five correlation measures using the Brown method, and only correlations with a $\rho$ value over 0.8 and a significance level below 0.06 were presented in the network. In a network, high average node degree, high clustering coefficient and high network density can depict how dense a network is and the tendency to form clusters (Banerjee et al., 2019; Rebollar et al., 2019). In a microbial co-occurrence network, the OTUs with the highest degree, highest closeness centrality and lowest study, OTU with degree greater than 10 , closeness centrality greater than 0.24 , and betweenness centrality lower than 0.011 was selected as the keystone taxa.

\subsection{Phylogenetic analysis}

Standardized effect size measure of mean nearest taxon distance (ses.MNTD) was used to quantify phylogenetic relationships between closely related taxa (Webb et al., 2002). Negative ses.MNTD value $(<0)$ suggests that species are more closely related than expected by chance (clustering), whereas positive value ( $>0$ ) indicates that species are less closely related than expected by chance (over dispersion). The calculation was implemented in the $\mathrm{R}$ environment (http://www.r-project.org) with the Picante package using the null model 'taxa.labels' (999 randomization) (Kembel et al., 2010).

\subsection{Statistical analysis}

One-way analysis of variance (ANOVA) was used to evaluate the effects of land-use type, seasonal change and soil depth on soil physiochemical properties, $\alpha$-diversity and the relative abundances of bacterial phyla in SPSS 19.0 (SPSS, Chicago, IL, USA). While the interacted effects of land-use, seasonal change and soil depth on soil physiochemical properties were assessed by PerMANOVA (permutations $=999$ ). The effects of land-use, seasonal change and soil depth on overall bacterium community dissimilarity were performed using 'adonis' and 'anosim' function within 'vegan' package in R 3.5.3.

Canonical correspondence analysis (CCA) was performed to identify the major factors driving bacterial distribution in maize field between two seasons as well as in two different land uses in spring and autumn. Soil factors including soil moisture, SOM, TC, DOC, DON, C/N ratio, $\mathrm{pH}, \mathrm{NO}_{3}{ }^{--} \mathrm{N}$, and $\mathrm{NH}_{4}{ }^{+}-\mathrm{N}$ were included in the analysis, while TN was eliminated as strong collinearity in the CCA. Permutation tests were applied to assess the significance of the partial effects of the factors.

The relative abundance of bacterial orders $(>0.1 \%)$ was analyzed in Statistical Analysis of Metagenomic Profiles (STAMP) software, where Welch's t-test was applied to compare the relative abundance of bacterial orders between maize field and woodland in spring and autumn, respectively. In addition, the heat-map of relative abundance of bacterial community at order level was demonstrated using the R package 'pheatmap' and 'ggplot2'.

\section{RESULTS}

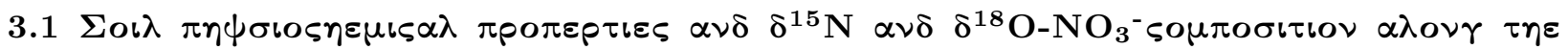 $\sigma o \iota \lambda \pi \rho \circ \varphi \iota \lambda \varepsilon$}

Soil physiochemical properties varied significantly between maize field and woodland in two seasons along the depth (Figures 2 and S1). Generally, all the soil properties except $\mathrm{NH}_{4}{ }^{+}-\mathrm{N}, \mathrm{NO}_{3}{ }^{-}-\mathrm{N}$ and $\mathrm{C} / \mathrm{N}$ significantly decreased along the depth, especially between the top 0-20 cm layer and other layers. While soil $\mathrm{C} / \mathrm{N}$ ratio showed the opposite trend along the depth for both land uses. Soil $\mathrm{NH}_{4}{ }^{+}-\mathrm{N}$ and $\mathrm{NO}_{3}{ }^{-}{ }^{-N}$ contents showed inconsistent trend along the depth in two land uses and seasons. 
Among different land uses, soil DON, DOC, C/N, $\mathrm{NH}_{4}{ }^{+}-\mathrm{N}$ and $\mathrm{NO}_{3}{ }^{-}-\mathrm{N}$ contents were all significantly higher in maize field than in woodland irrespective of season (Table 1). Among different seasons, soil $\mathrm{C} / \mathrm{N}$ was significantly higher in spring than in autumn irrespective of land use. Soil $\mathrm{NH}_{4}{ }^{+}-\mathrm{N}$ content was significantly higher in spring than in autumn only in maize field, and no significant difference of soil $\mathrm{NO}_{3}{ }^{-} \mathrm{N}$ content was found in maize field irrespective of season.

The dual isotope ratios of soil $\delta^{15} \mathrm{~N}$ and $\delta^{18} \mathrm{O}_{-} \mathrm{NO}_{3}{ }^{-}$are shown in Figure 3. It clearly showed that isotopes abundance from different land uses were separated from each other along the Y axis. Soil $\delta^{15} \mathrm{~N}$ $\mathrm{NO}_{3}{ }^{-}$composition from maize field fall between +5 fall between -5 composition from both land uses fall between $-5$

\subsection{Soil bacterial community structure}

Soil bacterial community structure and diversity was determined based on $16 \mathrm{~S}$ rRNA gene using pyrosequencing technique. In total, 7, 922 OTUs were obtained from 60 soil samples with the average number of 30,677 sequence per sample. Based on the relative abundance of OTU, we found that bacterial OTU richness (Figure 4a) and Shannon diversity (Figure 4b) in the maize field showed no significant difference with those of woodland irrespective of season $(P>0.05$ for both). However, the NMDS ordination based on the relative abundance of OTU using Bray-Curtis distance showed that bacterial community structure in maize field was clearly separated from those in woodland. Furthermore, bacterial community structure from both land uses showed a clear pattern along the depth and seasonal variance (Figure 4c), which was further confirmed by PerMANOVA and ANOSIM analysis based on different land uses $(P<0.01)$ and seasonal change $(P<0.05)$ (Table S1).

\subsection{Soil bacterial community composition}

Bacterial phylum with a relative abundance over $8.0 \%$ was considered as the dominant phylum in this study. As shown in Figure S2, the dominant bacterial phyla in maize field are Proteobacteria (mean 31.8\%), Chloroflexi (mean 14.4\%), Actinobacteria (mean 12.1\%), Acidobacteria (mean 11.4\%), Bacteroidetes (mean 9.2\%) and Gemmatimonadetes (mean 5.5\%). The relative abundance of bacterial phyla varied significantly in maize field from spring to autumn except Chloroflexi and Patescibacteria (Table S2). For example, Proteobacteria in the maize field along the depth in spring and autumn ranged from $57.1-22.2 \%$ and $47.6 \%-15.0 \%$, respectively. Actinobacteria and Bacteroidetes were in the range of $14.6-5.2 \%$ and $25.8-9.7 \%, 27.6-2.8 \%$ and $11.3-1.0 \%$, respectively. Additionally, the relative abundance of the dominant bacterial phyla in the woodland along the depth areProteobacteria (mean 23.2\%), Actinobacteria (mean 18.2\%), Acidobacteria (mean 17.9\%) and Chloroflexi (mean 12.2\%) (Figure S2). Only Actinobacteria, Acidobacteriaand Nitrospirae in the woodland responded significantly to seasonal change (Table S2). For example, Actinobacteria in the woodland along the depth in spring and autumn ranged from $22.2-10.9 \%$ and $31.8-14.1 \%$, respectively. Within the same season, it is quite clear that most of the dominant phyla except Chloroflex and Firmicutes showed significant differences $(P<0.05)$ between these two land uses in spring, while only Actinobacteria and Bacteroidetes showed significant difference in autumn. The relative abundance of Bacteroidetesshowed significant differences between different land uses for each season and seasonal difference in the maize field $(P<0.05)$, but no seasonal difference in the woodlands $(P>0.05)$.

We further compared the relative abundance of bacterial group (relative abundance $>0.1 \%$ ) at order level, and found that more bacterial groups showed significant variance between the two land uses in spring than in autumn (Figure 5), indicating that manure addition had a strong impact at the beginning. For example, the relative abundance of Flavobacteriales, Sphingobacteriales and Bacteroidales affiliated withBacteroidetes, Methylococales affiliated withGammaproteobacteria are significantly higher in the maize field than in the woodland in spring $(P<0.05)$, while no difference was found in autumn. While some bacterial groups showed lower abundance in the maize field than that in the woodland. For example, the relative abundance of Pyrinomonadales affiliated withAcidobacteria, Gaiellales affiliated withActinobacteria, Gemmatimonadales affiliated with Gemmatimonadetes, and Rokubacteriales affiliated withRokubacteria, are significantly lower in the maize field than in the woodland in spring, while there was no difference in autumn. 


\subsection{Factors driving the distribution of bacterial community structure}

We focused on the edaphic factors shaping bacterial community structure between different land uses (Figure $6 \mathrm{~A})$ and different seasons (Figures $6 \mathrm{~B}$ and $6 \mathrm{C}$ ) with $\mathrm{CCA}$ analysis. For different land uses, $\mathrm{SOM}\left(\mathrm{R}^{2}=0.74\right.$, $\mathrm{P}=0.001), \mathrm{C} / \mathrm{N}\left(\mathrm{R}^{2}=0.70, \mathrm{P}=0.001\right), \mathrm{NO}_{3}{ }^{-}-\mathrm{N}\left(\mathrm{R}^{2}=0.63, \mathrm{P}=0.001\right)$, soil $\mathrm{pH}\left(\mathrm{R}^{2}=0.57, \mathrm{P}=0.001\right)$ and moisture $\left(\mathrm{R}^{2}=0.53, \mathrm{P}=0.001\right)$ were strongly and significantly linked to the variance of bacterial community between different land uses (Figure 6A). All the tested factors except DOC and DON were highly correlated with the seasonal variance of bacterial community structure in maize field (Figure $6 \mathrm{~B})$, with $\mathrm{SOM}\left(\mathrm{R}^{2}=0.81\right.$, $\mathrm{P}=0.001)$, soil $\mathrm{pH}\left(\mathrm{R}^{2}=0.61, \mathrm{P}=0.001\right), \mathrm{NO}_{3}{ }^{-}-\mathrm{N}\left(\mathrm{R}^{2}=0.49, \mathrm{P}=0.001\right)$ and ammonium $\left(\mathrm{R}^{2}=0.44, \mathrm{P}=\right.$ $0.001)$ as the major factors.

In order to reveal phylogenetic community composition, standardized effect sizes of NMTD (ses.MNTD) was calculated. All of the ses.MNTD values obtained using the null model in both land uses were significantly negative (Figure 7), indicating that bacterial assemblages were phylogenetically clustered for all the soils along the depth. Furthermore, the ses.MNTD values showed an increased trend along the depth, indicating that bacterial phylogenetic clustering in the top soil is stronger than those in the deeper soils.

\subsection{Bacterial general co-occurrence network in different land uses}

We constructed four co-occurrence networks based on OTU-OTU correlations for different land uses and seasons, and found striking differences in the network size between land uses (Figure 8). There were three main clusters in maize field for both seasons, while only one main cluster in woodland. The networks of maize field in the spring and autumn (376 and 371 nodes) were more complex than that of woodland (278 and 334 nodes). Positive correlation (co-occurrences) displayed as edges was significantly higher than negative ones (mutual exclusions) in all the networks (Table 2). As shown in Table 2, network topological parameters varied in two land uses. The woodland network exhibited considerably higher average degrees, higher clustering coefficient and higher network density compared with the maize field network. The highest positive and negative correlation were recorded in maize field in the spring and woodland in the autumn, respectively, while the lowest positive and negative correlation were both recorded in the maize field in the autumn. More than $70 \%$ of all nodes were assigned to five dominant phyla includingProteobacteria, Acidobacteria, Actinobacteria andChloroflexi. Interestingly, Bacteroidetes was found as the dominant group in the maize field co-occurrence network, while not shown in woodland network (Figure 8).

\section{DISCUSSION}

Intensified livestock production system contributes significantly to environmental impacts including water, air and soil quality by altering the biogeochemical cycling of carbon, nitrogen and phosphorus (Bai et al., 2018; Leip et al., 2015; Pelletier \& Tyedmers, 2010). In this study, higher amount of nitrate was detected along the soil profile applied with cattle manure compared with the adjacent non-manured woodland, indicating higher risks of nitrate pollution even down to the subsurface soils with continued manure application. This result was in good agreement with a meta-analysis based on over 7000 cropland samples, which showed large accumulations of nitrate in the soil deep down to 4 meters (Zhou et al., 2016). Soil $\delta^{15} \mathrm{~N}_{-} \mathrm{NO}_{3}{ }^{-}$value further corroborated the high proportion of manure-derived nitrate in the maize field, which is consistent with previous research working on nitrate contamination sources in various environments (Fenech et al., 2012). While some researchers mentioned that the effect of manure addition on nitrate leaching varied with soil texture, climatic condition as well as the applied amounts (Gai et al., 2019; Maeda et al., 2003). Over-use of manure results in nitrate redundancy that gives rise to environmental concerns (Herrero \& Thornton, 2013), e.g., groundwater contamination, soil nitrogen losses. Similar result was also obtained from a long-term field study carried out in Nebraska in USA applied with different rates of manure application (Nguyen et al., 2013). However, in the above mentioned study, they suggested that manure if applied below or at the rates equal to crop $\mathrm{N}$ requirements has many benefits for food production and environmental protection. Recently, the possibility of substituting manure for commercial fertilizer has been addressed based on 141 published studies and concluded that recycling of livestock manure in agroecosystems would reduce nitrogen losses and increase food production especially in upland soils (Xia et al., 2017). Critical land management in 
crop production is therefore necessary in keeping sustainability of food production and agricultural systems.

Soil microbial diversity exhibited distinct response to the environment disturbance (Falkowski et al., 2008). In this study, manure addition had no significant impact on bacterial OTU richness and Shannon diversity in the maize field compared to woodland for both seasons, indicating that the change of land use in this site had no significant impact on bacterial $\alpha$ diversity. Generally, agricultural soil microbial diversity tend to be spatially homogeneous when compared to natural habitats because of the interference from human activities (Kennedy \& Smith, 1995). Soil bacterial diversity showed a decreasing trend from woodland to cropland (Zheng et al., 2017), which is contrast to our observation. Previous research also observed that soil bacterial diversity responds strongly to the land use change of Amazon rainforest and resulted in biotic homogenization in agricultural soils (Rodrigues et al., 2013). This discrepancy regarding the little difference of bacterial diversity between these two land uses was probably attributed to the addition of manure in the maize field. Additionally, not all the change of land uses would alter bacterial $\alpha$ diversity (Jesus et al., 2009). For example, soil bacterial diversity kept constant following the conversion of cropland to orchard in a degraded karst system (Liao et al., 2018). Our results suggested that the conversion of woodland to cropland did not significantly change bacterial $\alpha$ diversity.

Contrasting to the result of bacterial OTU richness between these two land uses, clear separation of bacterial structure between the maize field and woodland was detected even to the deep layers, which was further confirmed by PerMANOVA analysis. This difference may be explained by the following reasons. Firstly, manure contains numerous microbial resources including liable $\mathrm{C}$ and $\mathrm{N}$, providing soil nutrients for microbial growth, especially for the bacteria (Enwall et al., 2007; Sun et al., 2004). Secondly, manure application will change soil physical and chemical properties by altering soil aggregate stability, water and gas exchange, which in turn improving microbial living conditions (Guo et al., 2019). Additionally, manure harbors a large amount of microorganisms (Meng et al., 2019), and some of which will be introduced and persisted in soils from several days to several months depending on soil types and manure sources (Udikovic-Kolic et al., 2014). All these indicated that manure application favor microbial growth, enabling a shift in soil bacterial community composition (Peacock et al., 2001; Shen et al., 2010). The differences between these two land uses were more apparent in the network analysis as maize field networks harbor more modular than woodland. The co-occurrence network in woodland harbored a denser and highly connected bacterial community compared with that in the maize field, nevertheless, the bacterial community in maize field is more specialized with different ecosystem function.

Most interestingly, the shift of bacterial composition kept consistent along the soil profile, as site-specific pattern of bacterial community structure was detected in this study. Differences in spatial distribution of soil bacterial community was largely affected by the vertical gradients of soil properties (Jiao et al., 2018). The increase of ecological heterogeneity with increasing depth in our studied site may be attributable to the significant response of bacterial $\beta$ diversity along the soil profile. Similar to our study, researchers in four Alaska soil cores also indicated that microbial assembly process was mainly determined by environmental factors rather than depth (Tripathi et al., 2018). In both land uses, the ses.MNTD mean values deviated significantly from zero, indicating that bacterial assemblages had higher phylogenetic clustering than expected by chance. This finding is consistent with other previous studies (Horner-Devine \& Bohannan, 2006; Stegen et al., 2012), which indicated that soil bacterial community were more structured by environmental filtering in a wide range of environments. Significant correlation between ses.MNTD and depth further suggested that bacterial community are shifted from more phylogenetically clustered assembly to less along soil depth. Similar results have been found in various habitats, like Alaskan soil cores (Tripathi et al., 2018), Tibetan Plateau (Chu et al., 2016), which showed that environmental filtering are more important in the assembly of bacterial community in surface soils than in deeper soils.

In this study, we found higher concentrations of nitrate in the maize field with long-term applications of livestock waste. This raises the question about which bacterial species responded mostly promptly or persisted longer following manure addition in the context of high nitrate scenario. Pearson correlation analysis between the dominant bacterial groups and nitrate content suggested that nitrate was significantly correlated with 
phyla of Bacteroidetes $(P<0.001)$, Nitrospirae $(P<0.01)$, Firmicutes $(P<0.001)$, and Gemmatimonadetes $(P<0.001)$ in the maize field (Table S3), but not correlated with special groups in the woodland. Furthermore, many bacterial groups at phylum or order levels showed significant differences in the two land uses in the spring than in the autumn, especially Bacteroidetes. Accumulating evidence showed that Bacteroidetes is widely present in a range of habitats including plant (Thomas et al., 2011), soil (Lauber et al., 2009) and animal gut (Tajima et al., 1999). Their mammal origin might explain the higher abundance and sensitive response in the maize field especially in spring. Our result is consistent with a previous study by Wolinska and his colleagues (Wolinska et al., 2017), who suggested that Bacteroidetes could be recommended as a sensitive indicator for agricultural soil type. Additionally, Bacteroidetes is specialized in decomposing high molecular weight compounds such as polycyclic aromatic hydrocarbons and xenobiotics (Fernandez-Gomez et al., 2013), which could be explained by its copiotrophy life strategy exhibiting more responsive to rich available nutrients (Ho et al., 2017; Pepe-Ranney et al., 2016). The enrichment of this microbial group in response to the addition of exogenous manure, suggests their ability in processing complex organic matter in soils and therefore improving soil fertility.

\section{CONCLUSIONS}

Significant changes in soil nutrient availability with the addition of manure contributed to the separation of soil bacterial community structure between different land uses in our study. More sensitive bacterial groups were detected in response to the manure addition especially in the beginning. Bacteroidetes phylum was one of the most responsive groups to the addition of manure addition, which could be a potential bio-indicator for agricultural usage. These results provide solid and necessary information for a better understanding of the succession characteristics of bacterial diversity as well as the driving factors in the maize field receiving cattle manure over a long term. Bacterial diversity is beneficial to terrestrial ecosystem in increasing disturbance tolerance and maintaining ecosystem services. Network analysis further highlights strong differences in network structure between the maize field and woodland that is more related to ecosystem function. We propose that future research should focus on the microbial diversity and function in assessing environmental risks of manure disposal as well as strategies to reduce nitrate leaching.

\section{ACKNOWLEDGEMENTS}

This work was supported by the Program of Intergovernmental Cooperation in Science and Technology (2017YFE0109800). We thank Drs. Peng Li and Xuan Guo, Shuai Du, Yu Liang for their assistance in samples collection.

\section{CONFLICT OF INTEREST}

The authors declare no conflict of interest.

\section{References}

Ashworth, A. J., DeBruyn, J. M., Allen, F. L., Radosevich, M., \& Owens, P. R. (2017). Microbial community structure is affected by cropping sequences and poultry litter under long-term no-tillage. Soil Biology $\mathscr{E}$ Biochemistry, 114 , 210-219. doi:10.1016/j.soilbio.2017.07.019

Bai, Z. H., Ma, W. Q., Ma, L., Velthof, G. L., Wei, Z. B., Havlik, P., . . . Zhang, F. S. (2018). China's livestock transition: driving forces, impacts, and consequences.Science Advances, 4 (7). doi:ARTN eaar853410.1126/sciadv.aar8534

Banerjee, S., Walder, F., Buchi, L., Meyer, M., Held, A. Y., Gattinger, A., . . . van der Heijden, M. G. A. (2019). Agricultural intensification reduces microbial network complexity and the abundance of keystone taxa in roots. Isme Journal, 13 (7), 1722-1736. doi: 10.1038/s41396-019-0383-2

Bardgett, R. D., \& van der Putten, W. H. (2014). Belowground biodiversity and ecosystem functioning.Nature, 515 (7528), 505-511. doi:10.1038/nature13855

Caporaso, J. G., Kuczynski, J., Stombaugh, J., Bittinger, K., Bushman, F. D., Costello, E. K., . . . Knight, 
R. (2010). QIIME allows analysis of high-throughput community sequencing data. Nature Methods, 7 (5), 335-336.doi: 10.1038/nmeth.f.303

Chu, H. Y., Sun, H. B., Tripathi, B. M., Adams, J. M., Huang, R., Zhang, Y. J., \& Shi, Y. (2016). Bacterial community dissimilarity between the surface and subsurface soils equals horizontal differences over several kilometers in the western Tibetan Plateau. Environmental Microbiology, 18 (5), 1523-1533. doi:10.1111/1462-2920.13236

Edgar, R. C. (2013). UPARSE: highly accurate OTU sequences from microbial amplicon reads. Nat Methods, 10 (10), 996-998. doi:10.1038/nmeth.2604

Enwall, K., Nyberg, K., Bertilsson, S., Cederlund, H., Stenstrom, J., \& Hallin, S. (2007). Long-term impact of fertilization on activity and composition of bacterial communities and metabolic guilds in agricultural soil. Soil Biology \& Biochemistry, 39 (1), 106-115. doi:10.1016/j.soilbio.2006.06.015

Falkowski, P. G., Fenchel, T., \& Delong, E. F. (2008). The microbial engines that drive Earth's biogeochemical cycles. Science, 320 (5879), 1034-1039. doi:10.1126/science.1153213

Fenech, C., Rock, L., Nolan, K., Tobin, J., \& Morrissey, A. (2012). The potential for a suite of isotope and chemical markers to differentiate sources of nitrate contamination: A review. Water Research, 46 (7), 2023-2041. doi:10.1016/j.watres.2012.01.044

Feng, Y. Z., Chen, R. R., Hu, J. L., Zhao, F., Wang, J. H., Chu, H. Y., . . . Lin, X. G. (2015). Bacillus asahii comes to the fore in organic manure fertilized alkaline soils.Soil Biology \& Biochemistry, 81, 186-194. doi: 10.1016/j.soilbio.2014.11.021

Fernandez-Gomez, B., Richter, M., Schuler, M., Pinhassi, J., Acinas, S. G., Gonzalez, J. M., \& PedrosAlio, C. (2013). Ecology of marine Bacteroidetes: a comparative genomics approach. Isme Journal, 7 (5), 1026-1037. doi: 10.1038/ismej.2012.169

Gai, X. P., Liu, H. B., Liu, J., Zhai, L. M., Wang, H. Y., Yang, B., . . . Lei, Q. L. (2019). Contrasting impacts of long-term application of manure and crop straw on residual nitrate-N along the soil profile in the North China Plain. Science of the Total Environment, 650 , 2251-2259. doi:10.1016/j.scitotenv.2018.09.275

Guo, Z. C., Zhang, J. B., Fan, J., Yang, X. Y., Yi, Y. L., Han, X. R., . . . Peng, X. H. (2019). Does animal manure application improve soil aggregation? Insights from nine long-term fertilization experiments. Science of the Total Environment, 660 , 1029-1037. doi:10.1016/j.scitotenv.2019.01.051

Hartmann, M., Frey, B., Mayer, J., Mader, P., \& Widmer, F. (2015). Distinct soil microbial diversity under long-term organic and conventional farming. Isme Journal, 9 (5), 1177-1194. doi: 10.1038/ismej.2014.210

Herrero, M., \& Thornton, P. K. (2013). Livestock and global change: Emerging issues for sustainable food systems. Proceedings of the National Academy of Sciences of the United States of America, 110 (52), 20878-20881. doi:10.1073/pnas.1321844111

Ho, A., Di Lonardo, D. P., \& Bodelier, P. L. E. (2017). Revisiting life strategy concepts in environmental microbial ecology. Fems Microbiology Ecology, 93 (3). doi:ARTN fix00610.1093/femsec/fix006

Horner-Devine, M. C., \& Bohannan, B. J. M. (2006). Phylogenetic clustering and overdispersion in bacterial communities. Ecology, 87 (7), S100-S108. doi: 10.1890/0012-9658(2006)87[100:Pcaoib]2.0.Co;2

Jesus, E. D., Marsh, T. L., Tiedje, J. M., \& Moreira, F. M. D. (2009). Changes in land use alter the structure of bacterial communities in Western Amazon soils (vol 3, pg 1004, 2009). Isme Journal, 3 (10), 1222-1222. doi:10.1038/ismej.2009.98

Jia, W., Qin, W., Zhang, Q., Wang, X., Ma, Y., \& Chen, Q. (2018). Evaluation of crop residues and manure production and their geographical distribution in China. Journal of Cleaner Production, 188 , 954-965. doi:10.1016/j.jclepro.2018.03.300 
Jiao, S., Chen, W. M., Wang, J. L., Du, N. N., Li, Q. P., \& Wei, G. H. (2018). Soil microbiomes with distinct assemblies through vertical soil profiles drive the cycling of multiple nutrients in reforested ecosystems. Microbiome, 6 . doi:ARTN 14610.1186/s40168-018-0526-0

Ju, X. T., Kou, C. L., Christie, P., Dou, Z. X., \& Zhang, F. S. (2007). Changes in the soil environment from excessive application of fertilizers and manures to two contrasting intensive cropping systems on the North China Plain. Environmental Pollution, 145 (2), 497-506. doi:10.1016/j.envpol.2006.04.017

Kembel, S. W., Cowan, P. D., Helmus, M. R., Cornwell, W. K., Morlon, H., Ackerly, D. D., . . . Webb, C. O. (2010). Picante: R tools for integrating phylogenies and ecology.Bioinformatics, 26 (11), 1463-1464. doi:10.1093/bioinformatics/btq166

Kennedy, A. C., \& Smith, K. L. (1995). Soil microbial diversity and the sustainability of agricultural soils. Plant and Soil, 170 (1), 75-86. doi:Doi 10.1007/Bf02183056

Krapac, I. G., Dey, W. S., Roy, W. R., Smyth, C. A., Storment, E., Sargent, S. L., \& Steele, J. D. (2002). Impacts of swine manure pits on groundwater quality. Environmental Pollution, 120 (2), 475-492. doi:Pii S0269-7491(02)00115-X

Lauber, C. L., Hamady, M., Knight, R., \& Fierer, N. (2009). Pyrosequencing-based assessment of soil ph as a predictor of soil bacterial community structure at the continental scale. Applied and Environmental Microbiology, 75 (15), 5111-5120. doi:10.1128/Aem.00335-09

Lee, C. K., Barbier, B. A., Bottos, E. M., McDonald, I. R., \& Cary, S. C. (2012). The inter-valley soil comparative survey: the ecology of Dry Valley edaphic microbial communities. Isme Journal, 6 (5), 10461057.doi: 10.1038 /ismej.2011.170

Leip, A., Billen, G., Garnier, J., Grizzetti, B., Lassaletta, L., Reis, S., . . . Westhoek, H. (2015). Impacts of European livestock production: nitrogen, sulphur, phosphorus and greenhouse gas emissions, land-use, water eutrophication and biodiversity. Environmental Research Letters, 10 (11). doi:Artn 11500410.1088/1748$9326 / 10 / 11 / 115004$

Liao, H. K., Zheng, C. L., Li, J., \& Long, J. (2018). Dynamics of soil microbial recovery from cropland to orchard along a 20-year chronosequence in a degraded karst ecosystem.Science of the Total Environment, 639 , 1051-1059. doi:10.1016/j.scitotenv.2018.05.246

Lin, Y. X., Ye, G. P., Kuzyakov, Y., Liu, D. Y., Fan, J. B., \& Ding, W. X. (2019). Long-term manure application increases soil organic matter and aggregation, and alters microbial community structure and keystone taxa. Soil Biology $\&$ Biochemistry, 134 , 187-196. doi: 10.1016/j.soilbio.2019.03.030

Liu, T., Wang, F., Michalski, G., Xia, X. H., \& Liu, S. D. (2013). Using N-15, O-17, and O-18 to determine nitrate sources in the Yellow River, China.Environmental Science \&6 Technology, 47 (23), 13412-13421. doi:10.1021/es403357m

Maeda, M., Zhao, B. Z., Ozaki, Y., \& Yoneyama, T. (2003). Nitrate leaching in an Andisol treated with different types of fertilizers (vol 121, pg 477, 2003).Environmental Pollution, 124 (2), 355-355. doi:10.1016/S02697491(02)00477-3

Mayfield, M. M., \& Levine, J. M. (2010). Opposing effects of competitive exclusion on the phylogenetic structure of communities. Ecology Letters, 13 (9), 1085-1093. doi:10.1111/j.1461-0248.2010.01509.x

Meng, Q. X., Yang, W., Men, M. Q., Bello, A., Xu, X. H., Xu, B. S., . . . Zhu, H. F. (2019). Microbial community succession and response to environmental variables during cow manure and corn straw composting. Frontiers in Microbiology, 10 . doi:ARTN 52910.3389/fmicb.2019.00529

Nguyen, H. Q., Kanwar, R. S., Hoover, N. L., Dixon, P., Hobbs, J., Pederson, C., \& Soupir, M. L. (2013). Long-term effects of poultry manure application on nitrate leaching in tile drain water. Transactions of the Asabe, 56 (1), 91-101.doi:10.13031/2013.42593 
Peacock, A. D., Mullen, M. D., Ringelberg, D. B., Tyler, D. D., Hedrick, D. B., Gale, P. M., \& White, D. C. (2001). Soil microbial community responses to dairy manure or ammonium nitrate applications. Soil Biology E Biochemistry, 33 (7-8), 1011-1019. doi: 10.1016/S0038-0717(01)00004-9

Pelletier, N., \& Tyedmers, P. (2010). Forecasting potential global environmental costs of livestock production 2000-2050. Proceedings of the National Academy of Sciences of the United States of America, 107 (43), 18371-18374. doi:10.1073/pnas.1004659107

Pepe-Ranney, C., Campbell, A. N., Koechli, C. N., Berthrong, S., \& Buckley, D. H. (2016). Unearthing the ecology of soil microorganisms using a high resolution DNA-sip approach to explore cellulose and xylose metabolism in soil. Frontiers in Microbiology, 7 (703). doi:10.3389/fmicb.2016.00703

Powell, J. R., Karunaratne, S., Campbell, C. D., Yao, H. Y., Robinson, L., \& Singh, B. K. (2015). Deterministic processes vary during community assembly for ecologically dissimilar taxa. Nature Communications, 6 . doi:ARTN 844410.1038/ncomms9444

Rebollar, E. A., Bridges, T., Hughey, M. C., Medina, D., Belden, L. K., \& Harris, R. N. (2019). Integrating the role of antifungal bacteria into skin symbiotic communities of three Neotropical frog species. Isme Journal, 13 (7), 1763-1775. 10.1038/s41396-019-0388-x

Rodrigues, J. L. M., Pellizari, V. H., Mueller, R., Baek, K., Jesus, E. D., Paula, F. S., . . . Nusslein, K. (2013). Conversion of the Amazon rainforest to agriculture results in biotic homogenization of soil bacterial communities. Proceedings of the National Academy of Sciences of the United States of America, 110 (3), 988-993. doi:10.1073/pnas.1220608110

Shen, J. P., Zhang, L. M., Guo, J. F., Ray, J. L., \& He, J. Z. (2010). Impact of long-term fertilization practices on the abundance and composition of soil bacterial communities in Northeast China. Applied Soil Ecology, 46 (1), 119-124. doi:10.1016/j.apsoil.2010.06.015

Sigman, D. M., Casciotti, K. L., Andreani, M., Barford, C., Galanter, M., \& Bohlke, J. K. (2001). A bacterial method for the nitrogen isotopic analysis of nitrate in seawater and freshwater. Analytical Chemistry, 73 (17), 4145-4153. doi:10.1021/ac010088e

Stegen, J. C., Lin, X. J., Konopka, A. E., \& Fredrickson, J. K. (2012). Stochastic and deterministic assembly processes in subsurface microbial communities. Isme Journal, 6 (9), 1653-1664. doi:10.1038/ismej.2012.22

Sun, H. Y., Deng, S. P., \& Raun, W. R. (2004). Bacterial community structure and diversity in a century-old manure-treated agroecosystem. Applied and Environmental Microbiology, 70 (10), 5868-5874. doi:10.1128/Aem.70.10.5868-5874.2004

Sun, R. B., Zhang, X. X., Guo, X. S., Wang, D. Z., \& Chu, H. Y. (2015). Bacterial diversity in soils subjected to long-term chemical fertilization can be more stably maintained with the addition of livestock manure than wheat straw.Soil Biology \& Biochemistry, 88 , 9-18. doi: 10.1016/j.soilbio.2015.05.007

Tajima, K., Aminov, R. I., Nagamine, T., Ogata, K., Nakamura, M., Matsui, H., \& Benno, Y. (1999). Rumen bacterial diversity as determined by sequence analysis of $16 \mathrm{~S}$ rDNA libraries. Fems Microbiology Ecology, 29 (2), 159-169. doi: 10.1111/j.1574-6941.1999.tb00607.x

Thomas, F., Hehemann, J. H., Rebuffet, E., Czjzek, M., \& Michel, G. (2011). Environmental and gut Bacteroidetes: the food connection. Frontiers in Microbiology, 2 . doi:ARTN 9310.3389/fmicb.2011.00093

Tian, W., Wang, L., Li, Y., Zhuang, K. M., Li, G., Zhang, J. B., . . . Xi, Y. G. (2015). Responses of microbial activity, abundance, and community in wheat soil after three years of heavy fertilization with manure-based compost and inorganic nitrogen. Agriculture Ecosystems 83 Environment, 213 , 219-227. doi: 10.1016/j.agee.2015.08.009

Tripathi, B. M., Kim, M., Kim, Y., Byun, E., Yang, J. W., Ahn, J., \& Lee, Y. K. (2018). Variations in bacterial and archaeal communities along depth profiles of Alaskan soil cores. Scientific Reports, 8 . 
doi:ARTN 50410.1038/s41598-017-18777-x

Udikovic-Kolic, N., Wichmann, F., Broderick, N. A., \& Handelsman, J. (2014). Bloom of resident antibioticresistant bacteria in soil following manure fertilization.Proceedings of the National Academy of Sciences of the United States of America, 111 (42), 15202-15207. doi:10.1073/pnas.1409836111

Wang, S. Q., Zheng, W. B., Currell, M., Yang, Y. H., Zhao, H., \& Lv, M. Y. (2017). Relationship between land-use and sources and fate of nitrate in groundwater in a typical recharge area of the North China Plain. Science of the Total Environment, 609 , 607-620. doi: 10.1016/j.scitotenv.2017.07.176

Webb, C. O., Ackerly, D. D., McPeek, M. A., \& Donoghue, M. J. (2002). Phylogenies and community ecology.Annual Review of Ecology and Systematics, 33 , 475-505. doi:10.1146/annurev.ecolsys.33.010802.150448

Wolinska, A., Kuzniar, A., Zielenkiewicz, U., Izak, D., Szafranek-Nakonieczna, A., Banach, A., \& Blaszczyk, M. (2017). Bacteroidetes as a sensitive biological indicator of agricultural soil usage revealed by a cultureindependent approach.Applied Soil Ecology, 119 , 128-137. doi:10.1016/j.apsoil.2017.06.009

Xia, L. L., Lam, S. K., Yan, X. Y., \& Chen, D. L. (2017). How does recycling of livestock manure in agroecosystems affect crop productivity, reactive nitrogen losses, and soil carbon balance? Environmental Science \& Technology, 51 (13), 7450-7457. doi:10.1021/acs.est.6b06470

Yang, S. M., Malhi, S. S., Song, J. R., Xiong, Y. C., Yue, W. Y., Lu, L. L., . . . Guo, T. W. (2006). Crop yield, nitrogen uptake and nitrate-nitrogen accumulation in soil as affected by 23 annual applications of fertilizer and manure in the rainfed region of Northwestern China. Nutrient Cycling in Agroecosystems, 76 (1), 81-94. doi:10.1007/s10705-006-9042-x

Yang, Y. R., Li, X. G., Liu, J. G., Zhou, Z. G., Zhang, T. L., \& Wang, X. X. (2017). Bacterial diversity as affected by application of manure in red soils of subtropical China.Biology and Fertility of Soils, 53 (6), 639-649. doi:10.1007/s00374-017-1209-x

Yu, C. Q., Huang, X., Chen, H., Godfray, H. C. J., Wright, J. S., Hall, J. W., . . . Taylor, J. (2019). Managing nitrogen to restore water quality in China. Nature, 567 (7749), 516-520. doi:10.1038/s41586-0191001-1

Yu, Y. J., Wu, M., Petropoulos, E., Zhang, J. W., Nie, J., Liao, Y. L., . . . Feng, Y. Z. (2019). Responses of paddy soil bacterial community assembly to different long-term fertilizations in southeast China. Science of the Total Environment, 656 ,625-633. doi:10.1016/j.scitotenv.2018.11.359

Zheng, J., Chen, J., Pan, G., Wang, G., Liu, X., Zhang, X., . . . Zheng, J. (2017). A long-term hybrid poplar plantation on cropland reduces soil organic carbon mineralization and shifts microbial community abundance and composition. Applied Soil Ecology, 111 , 94-104. doi:10.1016/j.apsoil.2016.11.017

Zheng, Y. M., Cao, P., Fu, B. J., Hughes, J. M., \& He, J. Z. (2013). Ecological drivers of biogeographic patterns of soil archaeal community. Plos One, 8 (5). doi:ARTN e6337510.1371/journal.pone.0063375

Zhou, J. Y., Gu, B. J., Schlesinger, W. H., \& Ju, X. T. (2016). Significant accumulation of nitrate in Chinese semi-humid croplands. Scientific Reports, 6 . doi:ARTN 2508810.1038/srep25088

\section{Hosted file}

tables.docx available at https://authorea.com/users/299015/articles/428414-variation-ofnitrate-and-bacterial-diversity-along-soil-profiles-in-manure-disposal-maize-field-andadjacent-woodland 

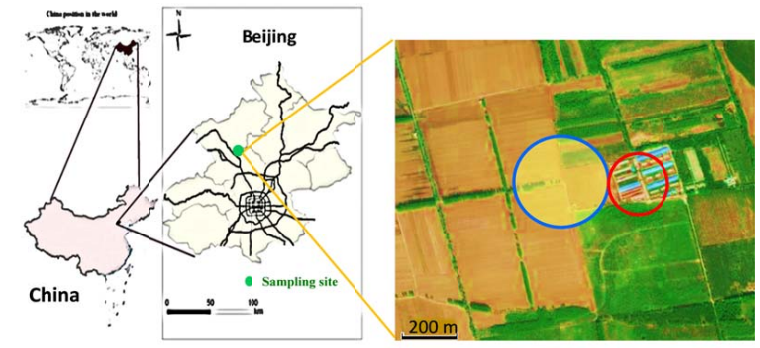

Figure 1 Location of sampling site in Yanqing District, Beijing, China.

There is a local dairy farm sitting within the area in red circle. Sampling plots are

located in the area in blue circle and the adjacent non-manured woodland 

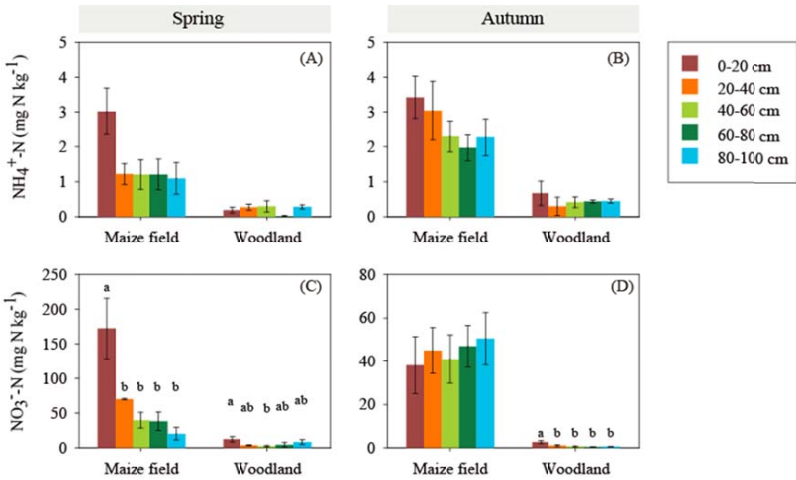

Figure 2 Soil ammonium (A and B) and nitrate contents (C and D) in two different land uses along the soil profile in spring and autumn. Lowercase letter on the bar indicates significant difference $(P<0.05)$ 


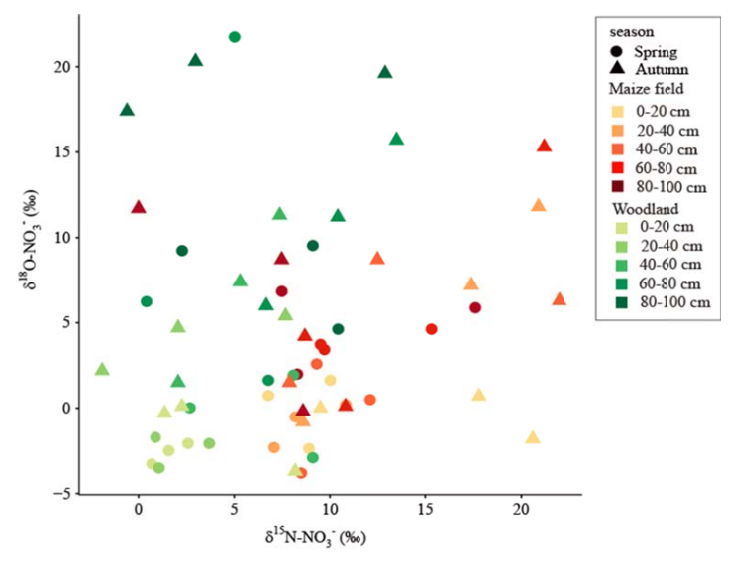

Figure 3 Soil $\delta^{15} \mathrm{~N}$ and $\delta^{18} \mathrm{O}-\mathrm{NO}_{3}{ }_{3}^{-}$distribution in two different land uses along the soil profile in spring and autumn 

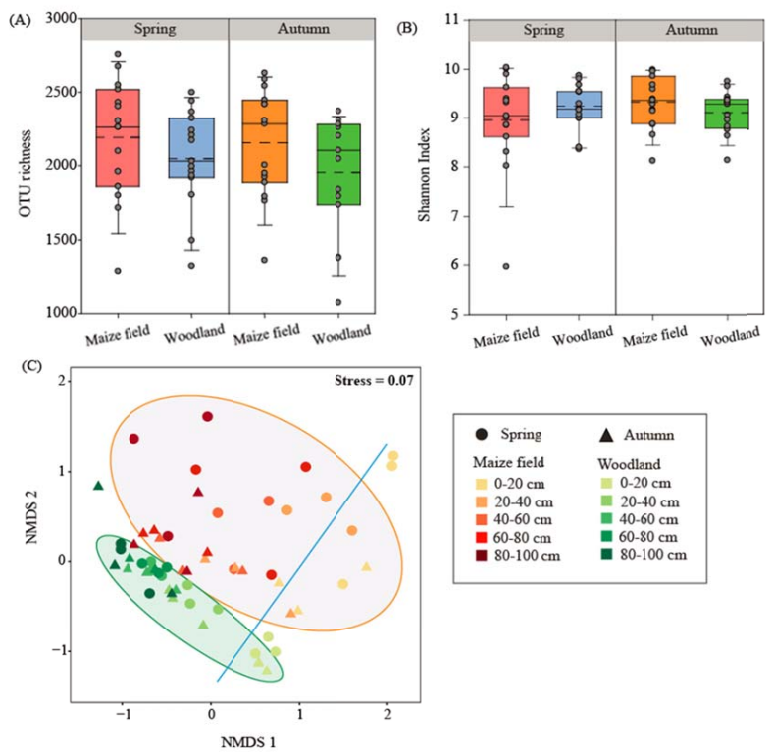

Figure 4 Bacterial OTU richness (A) and Shannon diversity (B) in different land use in spring and autumn; Non-metric multidimensional scaling (NMDS) plot based on Bray-Curtis dissimilarities (C) of the relative abundance of OTU along the soil depth. 


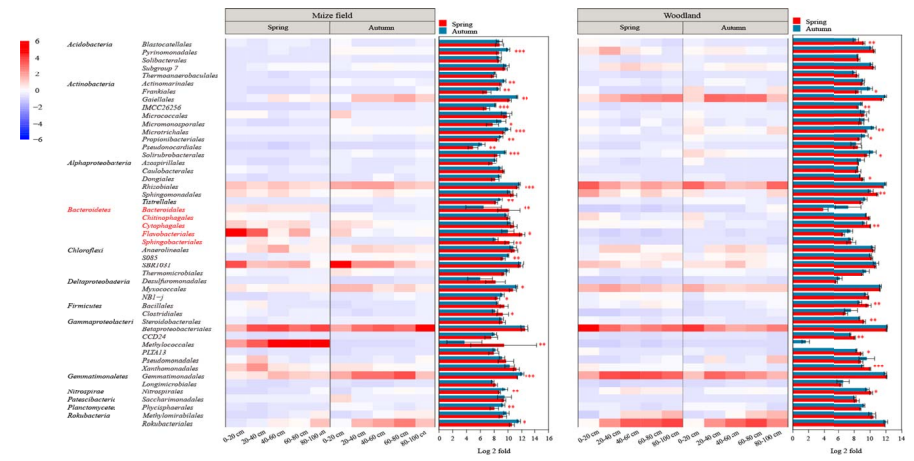

Figure 5 Heat map showing the variation and relative abundance of bacterial taxa at order level (relative abundance $>0.1 \%$ ) in maize field and

woodland in spring and autumn. *, **, **** represents $P<0.5,0.01,0.001$ in two seasons, respectively. 

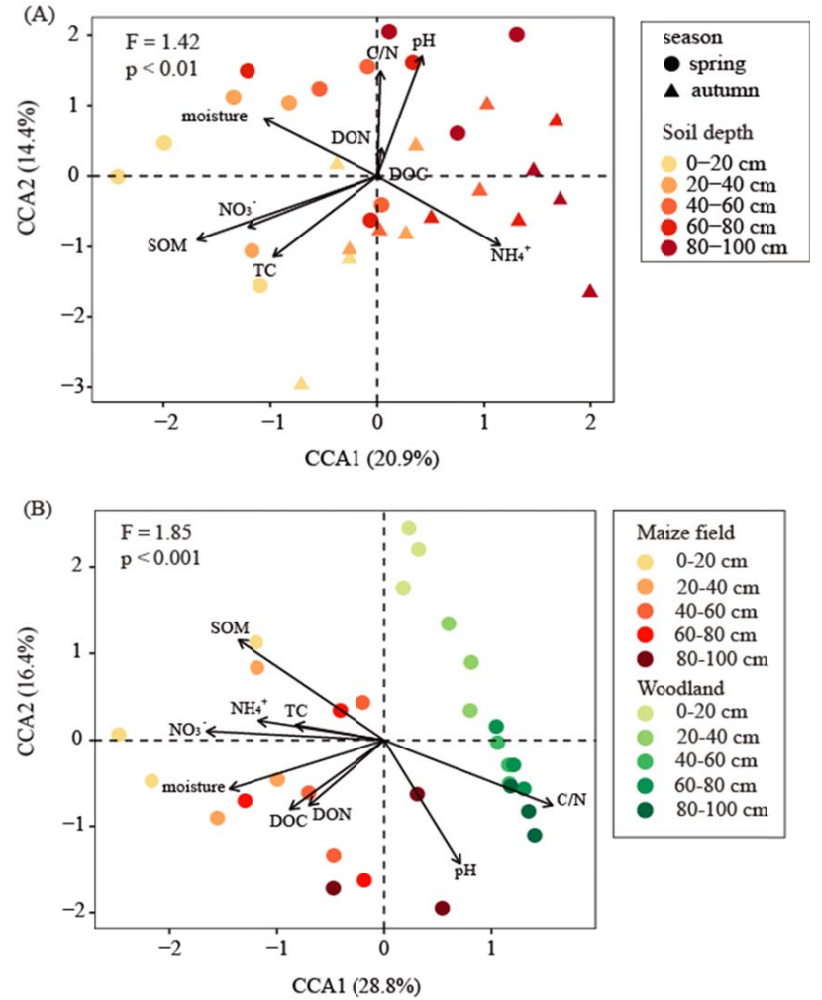

Figure 6 Canonical correspondence analysis of the relative abundance of bacterial OTU and soil properties among two seasons in maize field (A) and among two land uses in spring (B).

Abbreviation: SOM, soil organic matter; TC, total carbon; DOC, dissolved organic carbon; DON, dissolved organic nitrogen; $\mathrm{C} / \mathrm{N}$, the ratio of SOM and TN 


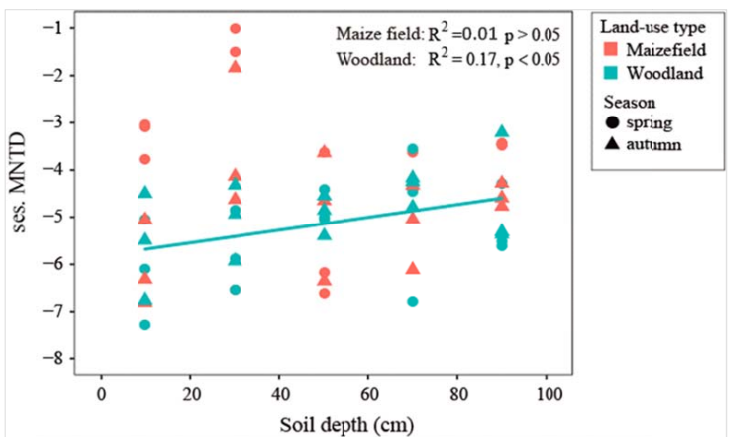

Figure 7 Variation of standardized effect size measure of mean nearest taxon distance (ses.MNTD) of bacterial communities and its relationship with depth in different land uses 

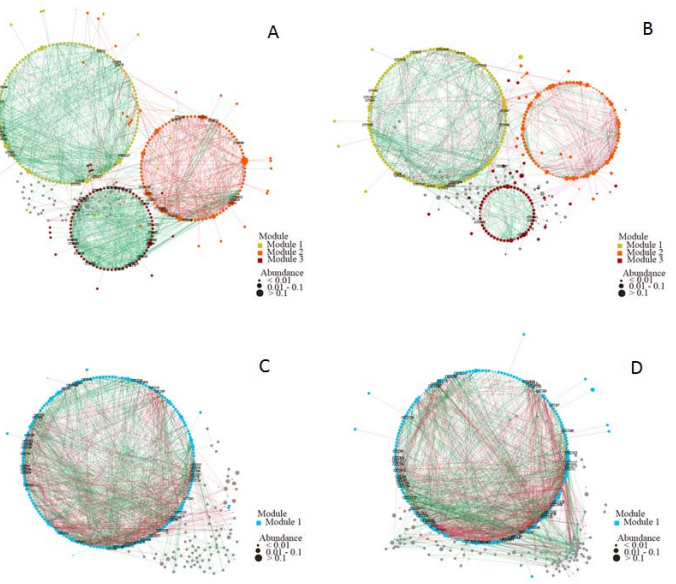

Figure 8 The correlation network of bacterial OTUs in maize field (A and B) and woodland (C and D) in spring (A and C) and autumn (B and D). The size of nodes represents relative abundance and the color of nodes indicates different cluster. Green and red line represent co-occurrence and mutual exclusion relation, respectively. 